\title{
Design and Fabrication of a Planar Inverted-F Antenna (PIFA) for LEO Satellite Application
}

\author{
Zin Thu Thu Lin, Hla Myo Tun \\ Email address: \\ ecdepartment.ytu@gmail.com (H. M. Tun) \\ ${ }^{*}$ Corresponding author
}

Department of Electronic Engineering, Yangon Technological University, Yangon Technological University, Yangon, Myanmar

To cite this article:

Zin Thu Thu Lin, Hla Myo Tun. Design and Fabrication of a Planar Inverted-F Antenna (PIFA) for LEO Satellite Application. American Journal of Electromagnetics and Applications. Vol. 8, No. 1, 2020, pp. 28-32. doi: 10.11648/j.ajea.20200801.14

Received: April 7, 2020; Accepted: April 22, 2020; Published: April 28, 2020

\begin{abstract}
The paper is mainly emphasizes on the microstrip patch antenna design for satellite applications. The specific objective of this study is to solve the research problem on finding the simple and compact design for small satellite application in real world. A new design of a Planar Inverted-F Antenna (PIFA) with the two height of $12 \mathrm{~mm}$ and $10 \mathrm{~mm}$ are proposed for low Earth orbit (LEO) applications in $\mathrm{S}$ band. The antenna is a single form antenna with the coaxial probe fed is used. CST Microwave Studio student version was used for the simulation of the antenna and matching design parameters. The antennas are obtained an efficient high return loss $-18.426 \mathrm{~dB}$ and $-18.169 \mathrm{~dB}$ at S11, the return loss bandwidth of $471 \mathrm{MHz}$ and $466 \mathrm{MHz}$. The radiation pattern results are analyzed beam width angle $85.1^{\circ}$ and $95.1^{\circ}$. Moreover, the peak directivity gain results $4.7 \mathrm{dBi}$ and $4.79 \mathrm{dBi}$, the absolute E-filed radiation effect are also presented. The actual measurement results for S11 parameter of return loss $-13.54 \mathrm{~dB}$ and $-14.2 \mathrm{~dB}$, return loss bandwidth of $510 \mathrm{MHz}$ and $425 \mathrm{MHz}$ are also fabricated with the comparison of simulation and fabrication process of PIFA antenna characteristics. The measurement of the return loss (S11) and return loss bandwidth were almost identical with the simulation.
\end{abstract}

Keywords: Antenna Height, $\mathrm{S}_{11}$, Return Loss Bandwidth, E-Field, LEO

\section{Introduction}

The Planar Inverted-F antenna (PIFA) has been extensively used due to the fact that it has very attractive profile. It has become popular due to its common use weather forecasting system. For the simplify design of antenna, it is commonly used in coaxial probe feeding methodology because of its was simplicity of PIFA microstrip patch antenna design $[1,2]$ By adjusting the position of the feed point the input impedance level can be varied. To increase the bandwidth, the PIFA is developed in actual world. The PIFA can be considered a direct extension of the probe for feed that it has by a radiating element or plate to increase its usable bandwidth BW [3]. The design variables of the effect for this antenna are the length, width, and height of the patch. Several modifications have been suggested to obtain a tradeoff between size, bandwidth and other properties of a PIFA. PIFA size can be reduced by shortening the antenna dimensions. However, by using this approach the impedance at the antenna terminals is affected which makes the radiation resistance reactive as well. The efficiency of PIFA is reduced by all losses suffered by its structure in its environment, including: mismatch losses, Ohmic losses and transmission losses etc. The bandwidth of a PIFA can be improved by modifying the size of the ground plane [4].

Nowadays, space technologies are become very popular. In space technology, Low earth Orbit LEO satellite can be used for weather forecasting, observation, radio and television broadcasting. LEO Communication system provide link between satellite and ground station. It can be transmitted telemetry and payload data from LEO satellite to ground station and ground station to satellite for tele-command data [5].

\section{Mathematical Analysis of PIFA}

The realized formula for the calculation of resonant frequency is given by equation 1 .

$$
l_{t}+\mathrm{h}-w_{s}+\mathrm{s}=\lambda / 4
$$




$$
f_{0}=\frac{c}{4\left(L_{S}+\mathrm{h}-W_{S}+S\right)}
$$

The symbol $\mathrm{c}$ is the speed of light, $\mathrm{W}_{\mathrm{S}}$ and $\mathrm{L}_{\mathrm{S}}$ are the width and length of the top plate of PIFA, $\mathrm{f}_{0}$ is the resonant frequency. Equation (2) means that the sum of the width and length of the top plate should be $\lambda / 4$. The operational frequency ranges from 2 to $4 \mathrm{GHz}$ frequencies to cover the most popular satellites applications [6]. The LEO system enable the access to space and a shorter development time to build with respect to all and they are very attractive. While considering such satellites, the antennas used in them should also be tiny and efficient depend on S band [7-14].

\section{Antenna Configuration}

The proposed PIFA design of the antenna which is nearly rectangular ground plane shape for the single band frequency. This antenna design parameters with the corresponding symbols and the values are summarizes in Table 1 .

Table 1. PIFA Antenna Design Parameter.

\begin{tabular}{ll}
\hline Antenna Parameters & Values $(\mathbf{m m})$ \\
\hline Ground plane length Lg & 70 \\
Ground plane width Wg & 100 \\
Height, h & 12 and 12 \\
Thickness, t & 1.6 \\
Shorting plate width Ws & 3 \\
Shorting plate length Ls & 13.63 \\
Feed width Wf & 18 \\
Feed length Lf & 13.63 \\
Patch length, Lt & 25 \\
Patch width, Wt & 40 \\
\hline
\end{tabular}

The PIFA design is used discrete port feed for $50 \mathrm{Ohms}$ impedance, which is nearly rectangular ground and patch shape for simply planar PIFA design form to be efficient is shown in figure 1 . The size of antennas between $100 \times 70 \mathrm{~mm}$ sizes for convenient LEO satellite applications is designed by using the FR-4 substrate which is low cost and flexible.

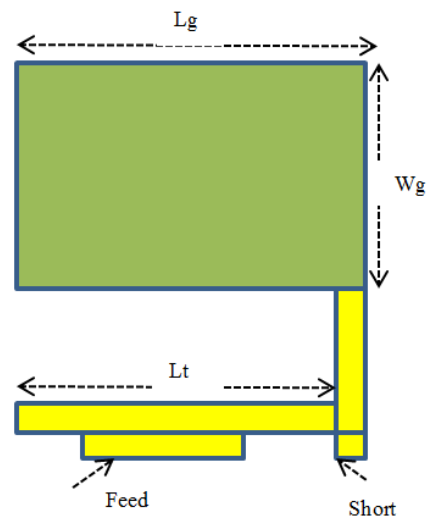

Figure 1. Geometry of Proposed PIFA antenna.

The antenna height $\mathrm{h}$ is filled with an air free space gap between the ground plane and top plate or radiating patch. The practical use of materials for the space between the ground plane and top plate is also exist in this investigation.
The dimensions of shorting plate and feeding plate have Ws $\mathrm{x}(\mathrm{h}+\mathrm{t})$ and Wf $\mathrm{x} h$ and this identification of symbol is described in Table 1.

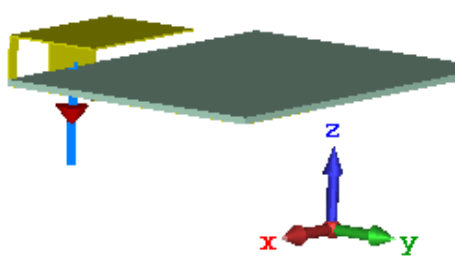

Figure 2. Simulation of PIFA Antenna.

The configuration of the PIFAs used for simulated and experimental study is shown in figure 2. For this studies, the procedure was adopted that only one parameter is used with a frequency domain solver setting in CST and its effects upon the PIFA performance while the frequency domain solver is also used.

\section{Simulation Results}

The significant effect in high frequency at $2.9 \mathrm{GHz}$ for $\mathrm{S} 11$ parameter is in the following figure 3. The antenna design has to fit it in the device of small terminal of height $h$ is $12 \mathrm{~mm}$ and $10 \mathrm{~mm}$ thus it is preferred in practical for the reduce size of planar IFA microstrip patch antenna. So, the effect of antenna has significant peak of S11 for high resonant frequencies is $-22 \mathrm{~dB}$ and the operated frequency for the return loss is $-18.4 \mathrm{~dB}$.

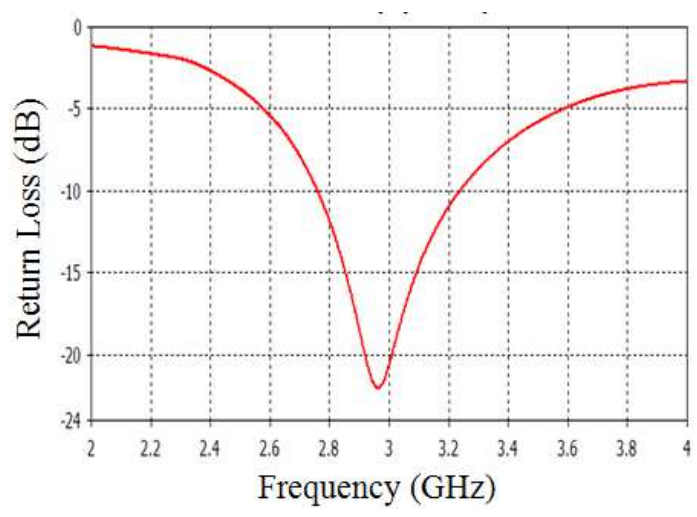

Figure 3. Return Loss (S11) Vs Frequency $(h=12 \mathrm{~mm})$.

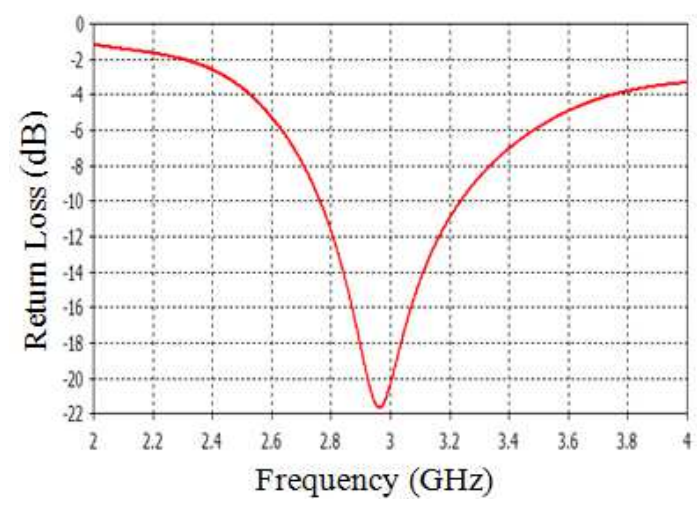

Figure 4. Return Loss (S11) Vs Frequency $(h=10 \mathrm{~mm})$. 
At $\mathrm{h}=10 \mathrm{~mm}$, the $\mathrm{S} 11$ is $-18.2 \mathrm{dBis}$ observed at $2.9 \mathrm{GHz}$. Therefore, But both of these antennas exhibits the return loss bandwidth of little high result in height of $12 \mathrm{~mm}$ and it is also exist pattern in almost uniformly in figure 4.

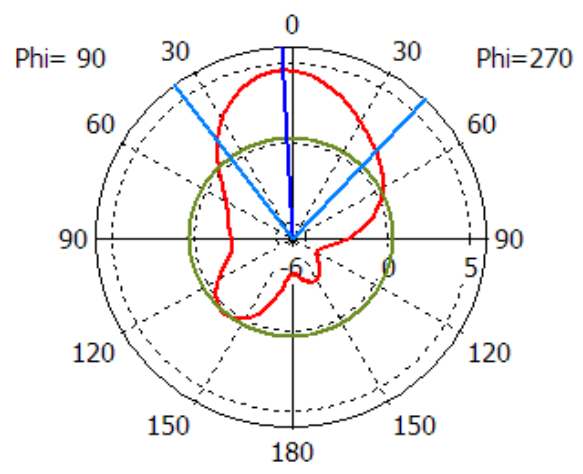

Figure 5. Radiation Pattern of $2.9 \mathrm{GHz}$.

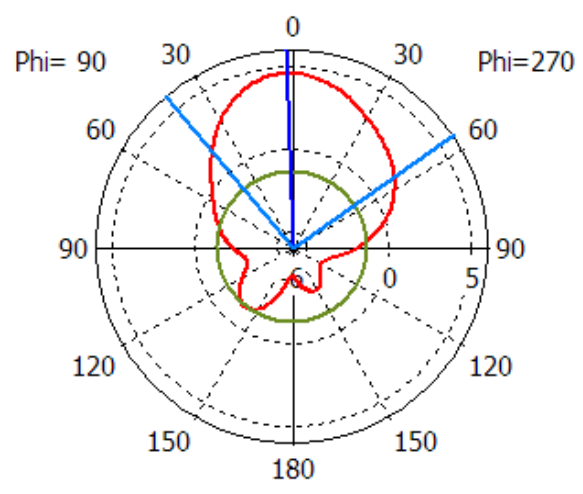

Figure 6. Radiation Pattern of $2.9 \mathrm{GHz}$.

The simulated radiation patterns for the two of PIFAs antennas are shown in figures 5 and 6 . There is no clearly significant fact of the backward radiation pattern. But, the two dimensional polar plot of the values of corresponding an angular $3 \mathrm{~dB}$ beamwidth are $80.1^{\circ}$ and $95.1^{\circ}$, the main lobe magnitude are $4.52 \mathrm{dBi}$ and $4.59 \mathrm{dBi}$ are observed in operated frequencies respectively. Thus, it can be denoted that the miniaturization of small height of antenna is an enhancement of characteristics of PIFA design.

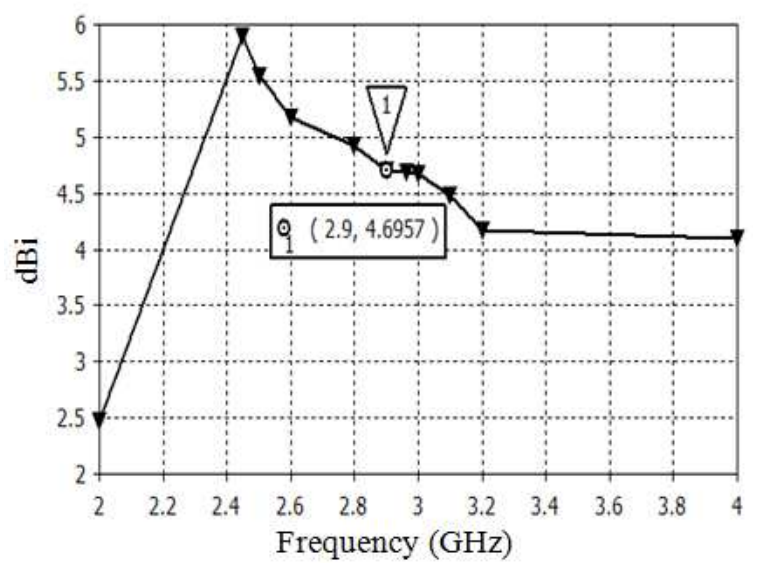

Figure 7. Directivity Gain Vs Frequency $(h=12 \mathrm{~mm})$.

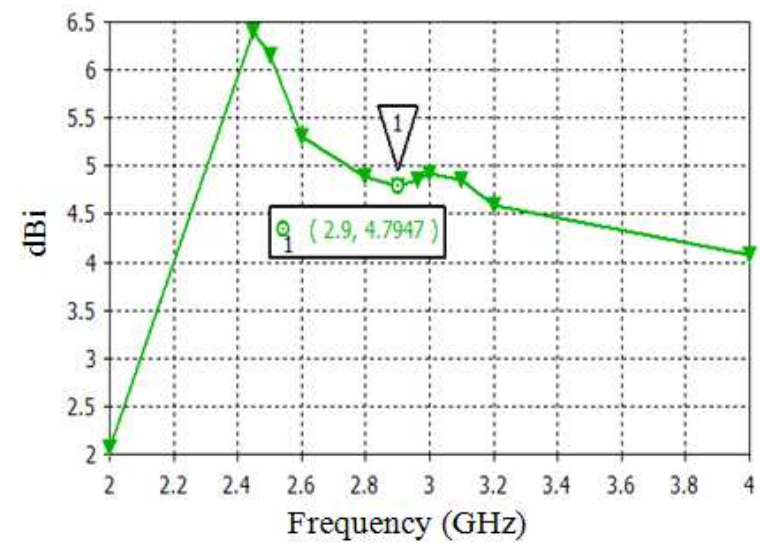

Figure 8. Directivity Gain Vs Frequency $(h=10 \mathrm{~mm})$.

The dimensional polar plot of the values of corresponding peak gain is $4.6957 \mathrm{dBi}$ at large height of antenna and small height of length of antenna is a peak gain of $4.7947 \mathrm{dBi}$. Therefore, the comparison of plot of $3 \mathrm{D}$ is seen to be increased the gain value for dedicate frequency ranges at 2.9GHZ in figures 7 and 8.

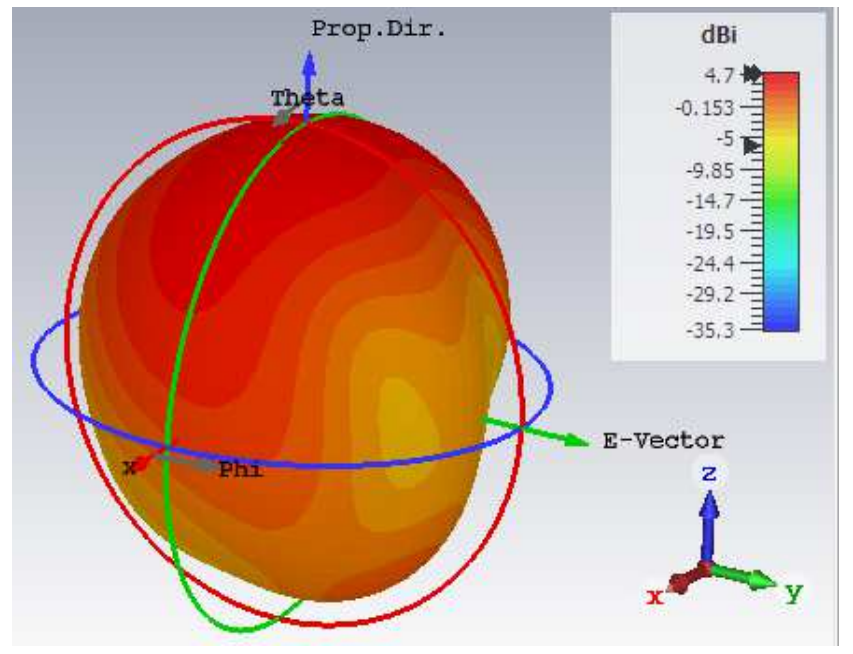

Figure 9. Peak Directivity Gain.

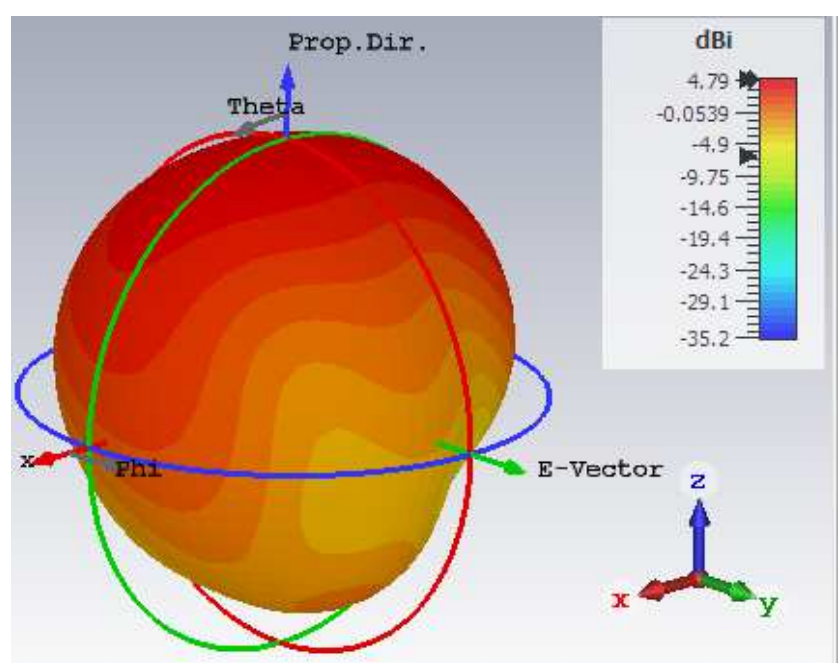

Figure 10. Peak Directivity Gain/. 
The directivity gain is seen to be significantly the requirement of LEO for frequency ranges at 2 to $4 \mathrm{GHz}$ with the corresponding representation. The effect of peak directivity gain at $2.9 \mathrm{GHz}$ is $4.69 \mathrm{dBi}$ and $4.79 \mathrm{dBi}$ in two of antenna height in $+z$ direction propagation in figures 9 and 10 .
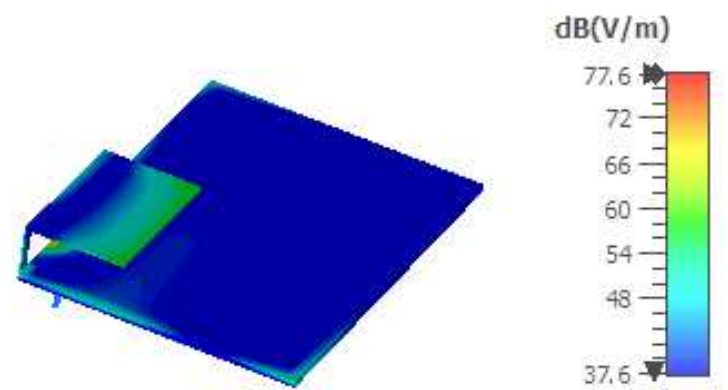

Figure 11. Absolute Electric Field (Initail).
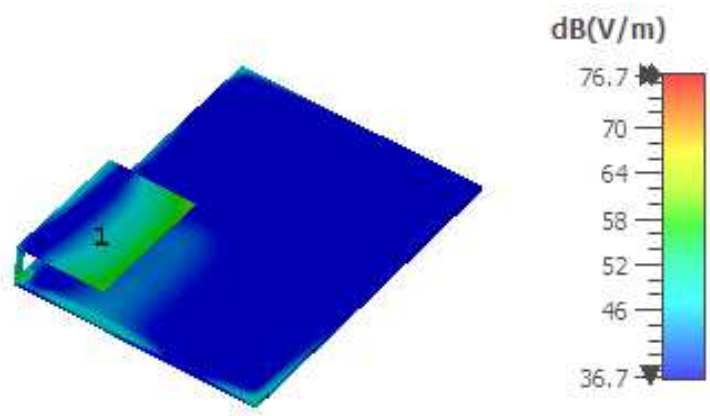

Figure 12. Absolute Electric Field (Final).

An electric E field at a point in space is a measure in CST how strong the force would be on a unit point charge. At $2.9 \mathrm{GHz}$, the absolute E-field is $77.6 \mathrm{dBV} / \mathrm{m}$ and $76.7 \mathrm{~dB} \mathrm{~V} / \mathrm{m}$ are observed. It can be shown that the corresponding color representation for high electric field as the above figures 11 and 12 .

\section{Fabrication and Measurement Results}

The milling machine is used MITS Electronics Eleven Lab for the routing area such as ground plane, short plate, feed plate and radiating patch for PIFA antenna. It is apparent that the PIFA antenna is easy to fabricate in the step by step activity from the ground to patch process in figure 13 .

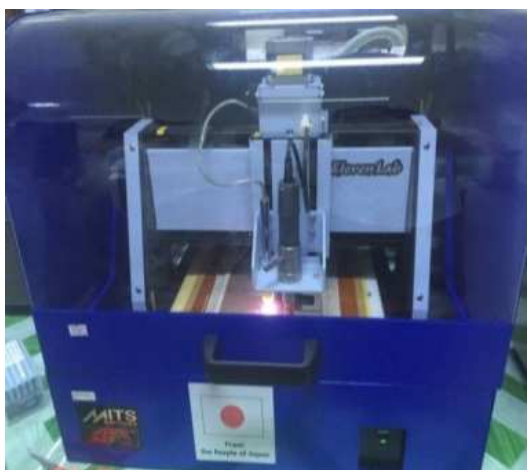

Figure 13. MITS Electronics Lab.

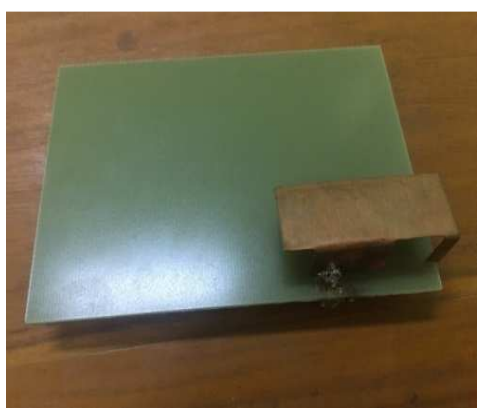

Figure 14. Experiments for PIFA Antenna.

In the experimental study of PIFA fabrication process, the requirement of components are FR-4 substrate with the $1.6 \mathrm{~mm}$ thickness, Copper sheet with the $0.5 \mathrm{~mm}$ thickness, $50 \mathrm{Ohms}$ coaxial connector with the soldering stand any other electronics cutter can be used as the necessary is shown in figure 14 .

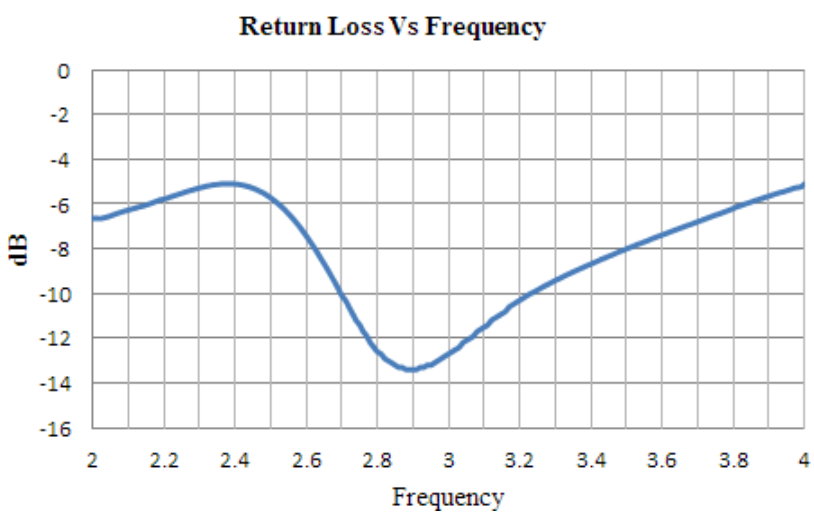

Figure 15. Measurement Results for Return Loss $(h=12 \mathrm{~mm})$.

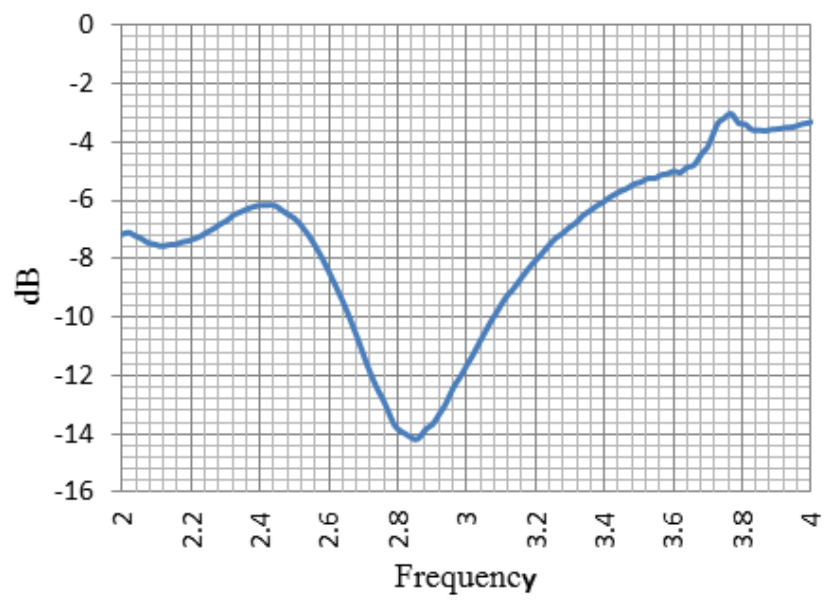

Figure 16. Measurement Results for Return Loss $(h=10 \mathrm{~mm})$.

The effects on return loss (S11) parameter of antenna measurement structure are presented. To measure the return loss in actual, the spectrum analyzer is necessary needed. In PIFA antenna, the domain setting is used in frequency domain solver setting for the start and stop frequency in figures 11, 12 and 13. After the calibration process, it can be denote that the peak value of $-13.54 \mathrm{~dB}$ and $-14.2 \mathrm{~dB}$ at resonant frequency $2.9 \mathrm{GHz}$. So, the actual measurement 
result less than simulation result in peak value and little shift or decrease of resonant frequency. Moreover, it was found that the effect of $\mathrm{BW}$ is $510 \mathrm{MHz}$ and $425 \mathrm{MHz}$ in $\mathrm{S} 11$ for measurement. Therefore it can be clearly seen that, the compatible wider value of RL bandwidth both of simulation and measurement in figures 15 and 16.

\section{Conclusion}

A single antenna PIFA is designed for LEO applications at $2.9 \mathrm{GHz}$ operate used in frequency domain solver. The design performances like the simulation, fabrication and measurement for PIFA are analyzed and optimized for the best results such as return loss in S11 in dedicated frequency band for miniaturization antenna size. Moreover, the electric field performances with the respective $\mathrm{S}$ band frequency are also be investigated. For the measurement performance, the necessary need of return loss, return loss bandwidth and quality can also be tested. Due to the current trend of miniaturization has brought each of antenna, the novel size of antenna with the proposed operating frequency $2.9 \mathrm{GHz}$ is more suitable for LEO satellite and thus this is widely used in antenna design for small satellites. The compact size of one unit (1U) which can be easily mounted on nanosatellite applications is more affected than any other conventional $\lambda / 2$ microstrip patch antenna.

\section{References}

[1] A. Joshi, 2014, "Design and simulation of planar inverted F antenna for ISM band applications using HFSS," International Journal of Scientific \& Engineering Research Volume 5, Issue 4.

[2] H. T. Chattha, Y. Huang and Y. Lu, 2014, "A study of parameters changes on the characteristics of planar inverted $\mathrm{F}$ antenna," Conference Paper, https://www.researchgate.net/publication/224502124.

[3] H. T. Chattha, 2012, "A comprehensive parametric study of planar inverted-F antenna," Wireless Engineering and Technology, https://www.SciRP.org/journal/wet.
[4] N. Kumar, April - June 2013, "Study of Planar Inverted-F Antenna (PIFA) for mobile devices," IJECT Vol. 4, Issue Spl 3.

[5] B. T. Ha and B. T. Guong, April 2019 Research, Design and Fabrication Microwave Modules of Receiver for NanoDragon Satellite at S Band, VNU Journal of Science: Mathematics Physics, Vol. 35, No. 2 (2019) 50-59

[6] N. Kumar and G. Saini, 2016, "A novel low profile planar inverted-F antenna PIFA for mobile handsets", https://www.researchgate.net/publication/283291935.

[7] O. Ceylan, A. R. Aslan and H. B. Yagcl, 09 May 2017, "Low cost S Band communication system design for nano satellites", https://www.researchgate.net/publication/252022776.

[8] Anoynomous, July 2017, "Low Earth Orbit Satellite Spectrum Access", Digital Transformation Monitor.

[9] L. Liu, X. Wang and P. Zhang, 2017, "Performance Analysis of Linear Polarization Antenna in $2.45 \mathrm{GHz}$ on Body Communications," International Journal of Applied Engineering Research, ISSN 0973-4562 Volume 12, Number 17, Research India Publications, http://www.ripublication.

[10] S. Gao, K. Clark, 2014 "Modern for small satellites", IEEE antenna and Propagation Magazine, https://www.researchgate.net/publication 224083262.

[11] J. M. Vieira, 2016, "Development of an UHF 2x2 microstrip antenna array antenna and Propagation for nano-satellites," Journal of Communication and Information Systems, VOL. 31, NO. 1.

[12] A. D. M. Herrái, "S-band antenna design for nanosatellite applications", Bachelor Thesis, Department of Radio Science and Engineering School of, sectrical Engineering Aalto University.

[13] H. T. Chattha, M. Nasir, Q. H. Abbasi, Y. Huang and S. S. AlJa'afreh, 2013, "Compact Low-Profile Dual-Port Single Wideband Planar Inverted-F Mimo Antenna," IEEE Antennas And Wireless Propagation Letters, Vol. 12.

[14] D. G. Fang, "Antenna theory and microstrip antennas" International Standard Book Number: 978-1-4398-0727-9, Nanjing university of science and technology. 